Article

\title{
The Gewirthian Principle of Generic Consistency as a Foundation for Human Fulfillment: Unveiling a Rational Path for Moral and Political Hope
}

Robert A. Montaña

\section{The Gewirthian Principle of Generic Consistency}

$\mathrm{F}$ ollowers of traditional modes of ethical thinking rightly approach postmodern philosophical methodologies with a certain enigma and suspicion due to the latter's tendency to swipe clean basic assumptions which had been historically accepted without question. Contemporary theorists conceptually dig their way into complex labyrinths of novel definitions not only to establish the neotericity of their paradigms but also to disengage themselves from the tyranny of dogmatic conclusions that may inhibit their suppositions from being enclosed by established systems of thought. When the Principle of Generic Consistency (PGC) was introduced by Alan Gewirth in his most popular work Reason and Morality (1978), it spurred numerous reactions, both pros and cons, ${ }^{1}$ as the principle offered to fulfill the utopian dream of establishing a rational foundation for human rights. The latter part of the book, together with subsequent articles and works, explained in detail how the principle could be applied to the intricacies of applied morality, such as the promotion of man's well-being, and consequently, the fulfillment of his existence. This paper deals with the same path of Gewirth; only this time, it seeks to construct a rational bridge between a PGC-based human self-fulfillment and the creation of a habitat that embodies hope for political harmony. Moreover, the PGC would not only be construed as the foundation for human rights, but also as a rational trail by which man's relation with his fellow could serve to develop an intersubjective enhancement of freedom and well-being.

Just as a thousand kilometer journey begins with a single step, so would the ultimate justification of political hope start with the question as to

1 Beyleveld reformulated the PGC and provided a voluminous work defending it against all known critiques. See Deryck Beyleveld, The Dialectical Necessity of Morality: An Analysis and Defense of Gewirth, Alan's Argument to the Principle of Generic Consistency (Chicago: University of Chicago Press, 1991). 


\section{R. MONTAÑA}

the possibility of a deductive reduction of moral principles; arguing in the negative, Gewirth explains that this process would merely confuse the interplay between that which justifies and that which is justified, explaining that "if the supreme principle is itself to be justified, then it becomes a justificandum, and as such it is logically posterior to and dependent on the justificans that justifies it."'2 Turning his attention to possible inductive modes-such as an appeal to empirical facts, elucidating generic principles from particular judgments, utilitarian means-end calculations, and by reflexive methods where the correctness of procedures determine substantial questions-Gewirth expressed similar intellectual suspicion due to the application of normative judgments to these particular foundations even before universal modes have been established.

Gewirth further avers that if ever there ought to be a principle which should fit the criterion of being first in its conceptual line, ${ }^{3}$ then this must be determinate, which means that it must not produce contents which contradict each other; also it must neither beg the question nor establish non-obligatory statements. He proposes that, in order to derive this, a thorough analysis of reason and action ought to be done. The strictness by which Gewirth accentuates the role of reason and its logical derivatives will have a bearing upon how an agent, drawing conclusions upon the implications of action itself, must adhere to what his particular deductive process elicits. In other words, Gewirth's utilization of reason as strict and minimal exposes his intention not to use intricate and complex patterns of inferences; rather, there is an attempt to entrench the notion that agents, in the exercise of basic rationality, must be morally congruent with the implications of action if they are to avoid selfcontradiction. Explained obliquely, agents who rationally proceed in accordance with what the normative structure of action dictates, avoiding circularity, will eventually adhere to the fundamental mandates of the supreme principle.

Proceeding to an analysis of action, Gewirth explains that certain generic features could be drawn out; they are generic because all agents who engage in action will have to possess these characteristics as the latter is inherently grounded upon action itself. From this point, he is clearly treading a linear path-with action being the necessary foundation for morality, and the generic features being the substratum of action. With these conceptual dots in place, Gewirth expounds that a thorough analysis of action educes a normative structure:

15.

2 Alan Gewirth, Reason and Morality (Chicago: The University of Chicago Press, 1978),

${ }^{3}$ Gewirth was not the first to make an attempt at a supreme moral principle; when he presented the principle in its initial evolutionary stage, Gregory Lycan included it and tried to analyze two other similar endeavors, viz., Hare's "necessary universalizability of moral judgments," Singer's "Generalization Principle," and Gewirth's "Principle of Categorical Consistency." After his detailed scrutiny, he concluded that the first two had "troublesome deficiencies" while Gewirth's principle did not exhibit such limitations. See Gregory Lycan, "Hare, Singer and Gewirth on Universalizability," in The Philosophical Quarterly, 19:75 (April 1969), 135. 


\section{THE GEMRTHIAN PRINCIPLE OF GENERIC CONSISTENCY}

... in that evaluative and deontic judgments on the part of agents are logically implicit in all action; and when these judgments are subjected to certain rational requirements, a certain normative moral principle logically follows from them. ${ }^{4}$

It is from here where Gewirth makes an analogous parallelism between verification and justification processes both in the natural sciences and in morality - the former counter-checking the truth value of a proposition by means of empirical data and the latter establishing moral action upon this aforementioned normative structure. It can be gleaned from these assertions that Gewirth was already laying out the groundwork by which the supreme moral principle can avoid charges of being arbitrary or subjective albeit the fact that its genesis stemmed from the agent's self-consistent judgment.

Having explicated the normative structure of action, Gewirth retrogressed back to commonalities which concurrently exist in agents who are similarly engaged - that they are assumed to proceed with unforced choice, intentionally moving towards a pre-conceived purpose or end ${ }^{5}$ which is deemed as good. ${ }^{6}$ Gewirth explains further:

By an action's being voluntary or free I mean that its performance is under the agent's control in that he unforcedly chooses to act as he does, knowing the relevant proximate circumstances of his action. By an action's being purposive or intentional I mean that the agent acts for some end or purpose that constitutes his reason for acting... Voluntariness and purposiveness hence comprise what I referred to above as the generic features of action .... ${ }^{7}$

Voluntariness and purposiveness, Gewirth further argues, exhaust the generic features of action-signifying that all other features would fall under either of the two major categories. An appeal to dualistic paradigms were

\footnotetext{
${ }^{4}$ Gewirth, Reason and Morality, 26.

5 Veatch questions Gewirth's intellectual procedures_-actually calling them misstepsbecause of the ambiguity clouding the demarcation between moral and nonmoral goods; he explained, at the same time, that the root of the problem lies in the attempt to justify ethics by means of language and logic rather than by means of ontology. See Henry Veatch, "Paying Heed to Gewirth's Principle of Categorical Consistency," in Ethics, 86:4 (July 1976), 285.

${ }^{6}$ Gewirth equates the notion of "good" with subjective value considered as the end point of action. He writes "This conception of worth constitutes a valuing on the part of the agent; he regards the object of his action as having at least sufficient value to merit his acting to attain it... These criteria of value need not be moral or even hedonic... Now 'value' in this broad sense is synonymous with 'good' in a similarly broad sense encompassing a wide range of nonmoral as well as moral criteria." See Gewirth, Reason and Morality, 49.

${ }^{7}$ Gewirth, Reason and Morality, 27.
} 


\section{R. MONTAÑA}

made as he expounded the reasons for this: that voluntariness involves the procedural aspect of action itself, while purposiveness is asserted as the substantive element; that voluntariness refers to means while purposiveness is the end; and that their relationship is similar to that of initiation to consummation. Whichever way the argument proceeds, it seems that Gewirth attempted to condense these features into their most primal categories implying that as discussions venture deep into principles, simplicity and universality assert themselves against multiplicity and particularities.

With Gewirth's conceptual structure in place, the argument moves from an analysis of action to the linguistic framework by which the agent expresses whenever purposive performance is pre-engaged. In simplified terms, the agent could be depicted as saying that "he does $\mathrm{X}$ for the purpose E." This statement, expressed descriptively and not ascriptively, is the starting point of what Gewirth calls the "dialectically necessary method." Differentiating this from the contingent process, he explains:

The dialectically necessary method begins from statements or judgments that are necessarily attributable to every agent because they derive from the generic features that constitute the necessary structure of action. The method I shall use here will be a dialectically necessary one, since this reflects the objectivity and universality reason achieves through the conceptual analysis of action. ${ }^{8}$

The methodology in this pursuit is not an ad rem procedure, i.e., one that begins from the internal to the external; rather, the issue revolves around the parameters of the uttering agent. Maneuvering more as a Kantian, Gewirth clarifies that the dialectical method begins from the standpoint of the agent, whereas, at this level, there are no assertoric claims as to whether what is being pursued is something which is good in the naturalistic sense. This element is crucial to the determination of the supreme principle because it avoids a lot of criticisms stemming from validity questions regarding the metaphysical status of the good which the agent is trying to achieve. On the other hand, it springs forth purely from the subject; but unlike Kant, Gewirth would ferry the argument beyond the confines of the will.

The judgment uttered by the agent with regard to the pursuit of what is perceived as good entails other judgments as a matter of logical consistency; this transfer is one basic characteristic of the dialectically necessary method and, as such, would be utilized by Gewirth to educe further implications. This entailment ought to be simple and direct, and at the same time, still confined within the parameters of the agent who has to subscribe to certain propositions which have been entailed by other accepted propositions. Awareness of these entailments, when applied to generic action, requires only the minimal exercise

${ }^{8}$ Gewirth, Reason and Morality, 43-44. 


\section{THE GEWRTHIAN PRINCIPLE OF GENERIC CONSISTENCY}

of reason; thus, any agent can be considered as rational if he posits these entailments.

An entailment that naturally follows from the agent's pursuit of what has been deemed as good for him is the assertion that freedom and well-being, features that are necessary for him to achieve his ends, are necessarily good. It is here where Gewirth's insistence upon logical consistency comes in-that this agent cannot, without contradicting himself, utter the goodness of that which is pursued without complementing his statement as regards the goodness of the freedom and well-being necessary for him to achieve this end. The positing of this necessity then entails another statement where "he logically must hold that he has rights to these generic features, and he implicitly makes a corresponding right-claim." When a deluge of critiques came with this transition to a right claim, Gewirth, together with other apologists, explained that, at this point, the claim still remained reflective-or has not yet gone beyond the agent. This transition is valid for Gewirth, further, because of his notion that action has both a deontic and evaluative structure, where the relation between the evaluative judgment (that freedom and well-being are necessary) and the deontic judgment (that he has rights to freedom and well-being) fit within the general framework of this structure.

The claimed rights ${ }^{10}$ are what Gewirth calls "generic" because they are logically deduced by all agents with the minimal use of reason; ${ }^{11}$ since freedom and well-being, further, are considered as necessary, then the right-claim concurrently takes upon a mandatory status. This consideration is radical for Gewirth because he takes it to its next inference stating that the agent "is entitled to redress and his respondents are subject to severe censure and other appropriate countermeasures, at least by himself, if the required conduct is not forthcoming." 12 It can be scrutinized that Gewirth, all throughout this process, has been laying the foundations on what an agent, desiring to achieve an end, must logically assent to without falling into contradiction.

The relationship between right-claims and action was described as essential by Gewirth; action, per se, cannot be successful unless certain

\footnotetext{
${ }_{9}^{9}$ Gewirth, Reason and Morality, 63.
}

10 Regis compared Gewirth's approach to rights as similar to that of Rawls's; he explains both as "oblique" which means "...one which, rather than try to justify ethical propositions directly, does so indirectly by tracing out the thoughts or ascertaining the beliefs of an agent who is thought to be in a special or privileged position." A few years after this article, Regis edited a compilation of essays in reaction to the PGC. See Edward Regis, Jr., "Gewirth on Rights," in The Journal of Philosophy, 78:12 (December 1981), 786 and Edward Regis Jr. ed., Gewirth's Ethical Rationalism: Critical Essays with a Reply by Alan Gewirth (Chicago: The University of Chicago Press, 1984).

11 Gewirth's notion of rationality as used in the Principle of Generic Consistency refers to the mind's acceptance of deductive entailments. He notes that "the criterion of 'rational' here is a minimal deductive one, involving consistency or the avoidance of selfcontradiction in ascertaining or accepting what is logically involved in one's acting for purposes and in the associated concepts." See Gewirth, Reason and Morality, 46.

${ }^{12}$ Gewirth, Reason and Morality, 67. 


\section{R. MONTAÑA}

conditions that lead to the achievement of goals are provided for. ${ }^{13}$ Thus, the agent who makes an internal right-claim would naturally include in this claim another entailed judgment-i.e., that other persons ought not to interfere with the prerequisites for the achievement of his end, viz., freedom and well-being.

Gewirth clarifies that the attribution of right is not arbitrary, because without sufficient rational justification, mere reciprocity would end up being discriminative. In this sense, the criterion of relevant similarities comes into purview as the agent realizes that the description which gave him this righti.e., the right claim for non-interference-is also present in other agents. Thus, taking into account the same rigorous demand of the logic where his claim is founded, he must respect the "self-claims" of other agents not to be interfered with their own rights. This inter-agent respect is an "exemplification of the formal principle of universalizability in its moral application, which says that whatever is right for one person must be right for any similar person in similar circumstances." 14

With these in place, Gewirth addresses all agents who are purposive and prospective, as the latter further includes all actions, that they should act in accord with the generic rights their recipients as well as their own. Designating this as the Principle of Generic Consistency (PGC), ${ }^{15}$ Gewirth combined the formal logical aspect of being consistent with the idea of respecting his own generic rights and those of others. ${ }^{16}$

${ }^{13}$ Seen in this way, action which is devoid of a normative structure would be incapable of achieving its end because in the absence of parameters to support efficiency and effectivity, agency would lose sight of its direction.

${ }^{14}$ Gewirth, Reason and Morality, 105.

15 Initially, this was termed by Gewirth as the Principle of Categorical Consistency (PCC) where the emphasis was centered upon the categorial rules of action rather than upon the latter's generic features. For purposes of clarity, the author quotes directly: "The categorial rules to which I have referred are the maximally general features which distinctively enter both into the choice of any specific rule of action and into the performance of any act. I call them 'categorial rules' because they apply not merely to one kind of act as against another but to the category of human acts as such, that is, to the maximally general features distinctive of all human action.." See Alan Gewirth, "Categorical Consistency in Ethics," in The Philosophical Quarterly, 17:69 (October 1967), 291.

16 The author, in his doctorate dissertation, defended the position that the PGC could establish itself compatibly with the Kantian Categorical Imperative. Although there is still a lot of contemporary debate as to whether Kant's Imperative was able to logically escape beyond the confines of the will, the methodology of Gewirth-moving from the dialectical implications of the agent's attempt to achieve his ends to the application of universalizability to these necessary conclusions-is wholly absent in Kant. It is also for this reason why Kant's concept of good is inevitably tied up with duty while Gewirth's good is linked to the normative structure of action instead. In simplified terms, Kant's universalizability of the good will is the basis of moral action; while, in Gewirthian philosophy, what is being universalized is the right-implications of action itself. See Robert Montana, An Exploration of the Foundational Paradigms of the Gewirthian Principle of Generic Consistency: Re-Structuring Apologies against Selected Critiques (Unpublished Doctorate Manuscript, UST Graduate School, Manila, March 2009), 426-427. 


\section{THE GEWIRTHIAN PRINCIPLE OF GENERIC CONSISTENCY}

\section{Human Fulfillment in the Light of the Supreme Moral Principle}

Human fulfillment in Gewirthian terms, following the path of the PGC, basically rests upon self-fulfillment. It would not be surprising to find a subsequent discussion of ideals like these after a supreme principle has been established-simply because it would be academically appropriate to link any form of principle, especially moral ones, to how it could advance the aspirations of man towards a more fruitful and satisfactory life. It could be possible that it is the basic instinct of man, like any other animal, to seek the achievement of its own well-being but, unlike those which fall under the same genera, it is through the capacities of man's reason that he is able to set up a greater $\operatorname{arena}^{17}$ where self-fulfillment can occur; it is also the complexities accompanying this intellectual terrain that prods man to intellectually scrutinize this development. Gewirth, for his part, averred that his analyses of selffulfillment are not historically based, ${ }^{18}$ but "rather dialectical, analytical, and systematic."19

Gewirth expressed discontent insofar as the ideal by which man's desires and capacities are maximized has been sidestepped in recent philosophical thinking. It can be observed, further, that most systematic forms of studies have transliterated themselves in naturalistic terms, signifying a shift where philosophy is now attempting to move towards a methodological path similar to the sciences. With this endeavor, certain abstract notions like human fulfillment or well-being is now understood in terms of political satisfactionor even humanity in terms of citizenship - as the latter could summarily be measured empirically. Additional constraints by legal parameters have further isolated transcendent ideas on fulfillment as the former may restrict actions that lead to man's achievement of basic goods, as when delivery of food is restricted by issues on sovereignty.

Dividing goods into three major dimensions, viz., basic, nonsubstractive and additive, Gewirth laid out the bases by which an agent must project his moral decision if he must, following the logical dictates of his agency, achieve to the fullest potential the well-being of all agents, including his own. Basic goods pertain to physical and psychological dispositions which lead to the attainment of projected ends; although this may be subjectively determined, it nonetheless revolves around the notion of necessary instrumentality where certain conditions-having food and clothing, or being sane or mentally balanced, for instance-are needed. Goods, further, are

17 Man's greater reasoning capacity is the source of such a "greater arena." Unfortunately, this greater power can also lead to man's abuse; for this reason, certain movements, like advocacies against speciesism, are propagated.

18 Although historical grounding gives meaning to moral theories, Gewirth emphasized the primacy of establishing human fulfillment upon a principle which has been dialectically educed. Only after this fulfillment has been provided enough conceptual roots would it be able to throw itself out as a significant element of human history.

19 Alan Gewirth, Self-Fulfillment (USA: Princeton University Press, 1998), 6. 
nonsubstractive if the agent suffers no diminution compared to his original state; thus, an agent would possess these goods if relationally and minimally, what he has obtained continues to be in his possession. Additive goods are achieved if there is a rise in the general level of purpose-fulfillment as the agent continues to acquire or lose goods in his effort to continuously rise above his previous predicament.

Several further distinctions were made as to man's aspiration that leads to his fulfillment and that of his capacities leading to fruition. Although these distinctions may be reduced simply to a subjective and an objective understanding of man's attempt for perfection through the acquisition of goods, the conceptual relations between the two modes may end up defining the kind of moral approach needed to actualize this. Several philosophies have had to deal with conflicts between human-aspiration and state-defined capacity-fulfillment leading to the epistemic applications of power structures that led to the oppression of individual rights for the sake of the "common good" or "evolutionary development."

It would not be surprising for the Gewirthian paradigm to address the aforementioned concepts in relation to the mandates of the supreme moral principle. The PGC adheres to the notion of egalitarianism and universality as far as the achievement of freedom and well-being of every agent is concerned; thus, when rationality is invoked for moral purposes and logical consistency between fulfillment and the PGC is established, then it would naturally follow that agents must allow all other agents, having relevant similarities, the basic right to determine the effectuation of their aspirations and direction of their capacity-fulfillments. This is done, as mentioned, with intersubjective rationality that basically eliminates tyrants or oppressive moralities-like Nazism, for instance-that seek to elevate one's own fulfillment to the detriment of other persons. Gewirth further exposes other circumstances which are of a mixed nature, like that of adultery, where the aspiration for love is fulfilled while, at the same time, violating the well-being of the violated spouse.

Acting in accord with the rights of one's recipients as well as one's own basically would have other levels of conflicts especially when in real life crises, economic actualities give rise to the realization that resources are scarce, or that circumstances may not favor others; in this sense, the supreme moral principle mandates the maximum accommodation of all these rights so that the well-being of others are raised by additive goods, maintaining, at the same time, one's nonsubstractive state. This ought to be done especially in situations where helping others would not have any substantive effect upon one's own goods. Although Gewirth has provided numerous applicative examples for the PGC, novel problems would crop up even after his demise; it is here where interpretative paradigms would be utilized without diminution as regards the basic tenets of the principle.

Gewirth exposed the notion of the fulfillment of man's capacities as the key to good life; although there are various interpretations of what constitutes the good in life, Gewirth turns to the supreme principle. True to 


\section{THE GEWIRTHIAN PRINCIPLE OF GENERIC CONSISTENCY}

the PGC, where the exhaustion of the generic features is integrated to freedom and well-being, the latter's maximization would lead not only to successful action but to the perfection of life itself. As regards the subsequent rights stemming from these features, Gewirth explains that as "all persons have rights to freedom and well-being, they have to this extent rights to develop the personalist morality of the good life." 20 From these words, it can be deduced from Gewirth that a thorough understanding and application of the PGC would prescribe a mutual assertion of generic rights which, if applied with full accommodation, would create a milieu conducive for the development of capacities leading to an existence well-lived.

Freedom as the foundation of personalist moralities has been explained by Gewirth as understood in the light of the PGC's mandate for non-interference by other persons as agents attempt to achieve their good. In a positive sense, it is practically freedom of choice as to the performance of one's actions. Ideally, this ought to be infinite as far as man's potentialities are concerned except for the limitations imposed by the PGC - that in the exercise of one's freedom, the principle of universalizability is applied; this, in short, establishes an inter-relational limitation maximizing freedom without trampling upon the principle-established right of each agent. Placing the concept of freedom within the parameters of the supreme principle basically integrates rationality in the exercise of one's rights. While agents are aware of their own rights to achieve their ends, their adherence to the supreme principle will, at the same time, prevent them from certain behavior patterns that would holistically be detrimental to their generic rights as a whole. Drug addicts and smokers, for instance, cannot be totally free to consume recklessly because such would be detrimental to their own well-being as well as of other agents; this would create an illogical scenario where freedom is upheld against wellbeing.

On the other hand, well-being as the foundation of personalist moralities is an integral element of purposiveness, earlier explained by Gewirth and understood within the normative structure of action. Since good is inevitably tied up with purposiveness, its three dimensions, viz., basic, additive and nonsubstractive, must be substantially complete in each agent in order for successful action to ensue; this would lead to the fulfillment of the agent's capacity leading to good life. In this sense, well-being complements freedom because the latter, per se, cannot serve for man's fulfillment as the lack of purposiveness would lead moral action, though free, out of touch with man's goodness, free falling even to his irrational impairment.

Before venturing into the conceptual relations between aspiration and fulfillment, and human dignity as the basis of rights, it would be worthwhile to insert a basic element of fulfillment which has been overlooked by most moral systems - the idea of duty to oneself. The dialectical method by which the PGC is founded begins from the agent asserting the necessity of freedom and well-being for the achievement of his ends; it is from this assertion that a right-

\footnotetext{
${ }^{20}$ Gewirth, Self-Fulfillment, 109.
} 


\section{R. MONTAÑA}

claim is made, and from this right claim comes the notion that others ought not to interfere and, finally, that he also should not concurrently interfere with the right of others. In actual moral decisions, however, it would be difficult to rely on this reasoning process everytime a choice is offered. Due to this awareness, Gewirth is adamant as regards the development of virtue-a long range disposition for agents to think and act in terms of the supreme moral principle. Thus, it can be considered that one of the primary duties of the agent is to attune his mind and action to the proddings of the PGC. Further, although it would be redundant to remind agents to respect their own rights, Gewirth insists that it would be practically difficult for them to esteem the freedom and well-being of others if there are vices still lurking within their own personalities. Agents, as a generic whole, who follow duties to themselves would, by the principle of generalizability, ${ }^{21}$ eventually facilitate the fruition of the PGC as an egalitarian and universalist moral principle.

In a pluralistic society where most statements and paradigms are questioned almost automatically, the interplay between the fulfillment of aspirations and capacities may be more complex when applied. Gewirth raised certain issues where aspirations may not actually be at par with what is considered as "the best"- the actualization of the potentialities of the agent. In other words, such a high standard of excellence may raise the question as to whether man should aspire for it, or even exert extra effort to achieve this level. Gewirth, however, adheres to the notion that both are interconnected; explaining more as a naturalist than an idealist, he expressed that the best or the end is basically not defined but is a product of a learning process. It is through the effectuation of man's various aspirations that he comes to realize the capacities that define his being, and consequently, answer the question as to how he can fulfill his aspirations by taking up a realistic account of his capacities.

Shifting attention to the nature of human dignity as a basis for human rights, Gewirth admits that it was at least the Kantian ideal- that it is in accord with rationality to attribute dignity to every other man - that became the philosophical stone upon which the Universal Declaration established entitlements to economic, social and cultural rights for all human beings. Clarifying that the dignity in humanity is not deduced empirically, but rather inherently, Gewirth explains that there is no need for human beings to attain certain kinds of goods or even behave in certain ways in order for them to attain rights; instead, it is their humanity that becomes the antecedent or moral

${ }^{21}$ Marcus Singer charges that Gewirth used his generalization principle, cloaking it with another term, "the principle of universalizability." The author, however, thinks otherwise because Gewirth, in a previous article, reiterated that the generalization principle should be corrected by making "appropriate additions." If both are synonymous, then Gewirth would be illogically relying upon what he has criticized to be insufficient. See Marcus Singer, "On Gewirth's Derivation of the Principle of Generic Consistency," in Ethics, 95:2 (January 1985), 297 and Alan Gewirth, "The Generalization Principle," in The Philosophical Review, 73:2 (April 1964), 230 and Marcus Singer, Generalization in Ethics: An Essay in the Logic of Ethics with the Rudiments of a System of Moral Philosophy (New York: Atheneum, 1971). 


\section{THE GEWRTHIAN PRINCIPLE OF GENERIC CONSISTENCY}

justification of the right itself. Even though some theological or cosmological justifications have already been historically founded, purely rational modes would find that such is already inherent in man, because unlike other animals, he acts purposively, understanding at the same time what he is pursuing. ${ }^{22}$

With these considerations, it can be seen that the PGC as a principle has delved into the notion of humanity's attempt for self-fulfillment; by espousing reciprocal respect of each other's freedom and well-being, a rational justification for human dignity is paved, leading towards a correlative respect for each other's claim for non-interference. Creating an environment of virtue by which these are practiced, the continuous and unabated exercise of satisfying these right claims would eventually allow aspirations and capacities to be fully actualized.

\section{Moral and Political Hope Unveiled through Human Fulfillment}

Although no direct discussion as regards the link between the PGC and hope can be found in Gewirth, the author believes that this path is a natural corollary to aspiration and capacity fulfillment. As blueprint after blueprint of theoretical ethics are applied to the real world, where callous and hardened encumbrances to moral virtues are found, it would not be surprising for these frameworks to raise a little excitement at the beginning, causing intellectual commotion for a time, but then ending up calcifying in academic stockpiles. Possible sorry schemes like these have nonetheless stirred up hopes for change, where the idea itself connotes certain presuppositions, like an irrational moral and political situation that is beset by logical inconsistencies, unanswered questions, and vague ideas as to what ought to be the correct scenario. With all of these, hope comes into the picture, signifying nothing but a change from what is wrong to what is ideally right. ${ }^{23}$

Agents who hope as expressions of their political aspirations could then find themselves an avenue for fulfillment based upon the proper understanding and implementation of virtue as applied in the field; the

22 It seems that Gewirth, at this point, merely reiterates what has already been established historically or even dogmatically by most religious, scientific and political institutions. However, his insistence on human reason and its purposive action towards moral or even nonmoral ends as the basis of dignity exposes his position as regards the more universal application of the PGC. The author agrees with this because establishing human dignity upon institutional impositions would be placing the horse before the cart-reversing the ethical notion that abstract human entities must first be founded and validated upon individual right considerations.

${ }^{23}$ Hope, however, ought to be translated to action - one that is capable of adjusting to the complexities of the contemporary scenario. In this period of inter-connectivity, for instance, Grant and Keohane raises the problem as regards the application of global accountancy in the absence of global democracy; by identifying accountability mechanisms, he hopes to identify correlative opportunities to improve protections against abuses in the global scale. This attempt, one among myriads of others, shows that visionaries in politics are still present. See Ruth Grant and Robert Keohane, "Accountability and Abuses of Power in World Politics," in The American Political Science Review, 99:1 (February 2005), 29. 


\section{R. MONTAÑA}

secularization of virtue, beginning from Aristotle, and its implications in religious life and even in politics, has widened the base upon which contemporary literature can intellectually manipulate the concept to integrate it as an element of solution to the complexities of agent-to-agent relations. Gardner ${ }^{24}$ attempted to establish correlates between party politics and virtue stating that based upon the former's assumptions, electoral victory is not an intra-party victory but is, rather, a "victory of truth over error." Burtt, ${ }^{25}$ on the other hand, questioned two current distinctions for politics of virtue, viz., liberal and republican, arguing that it is the private and public orientations that ought to be distinguished because the former distinction delved into the public domain. With these arguments, abstractions of purely ethical concepts like virtue can and should be contextualized to solve particularized problems governing day-to-day political hindrances to aspiration and capacity fulfillment. Pushing the concept even further, the PGC-founded aspiration and capacity fulfillment thus becomes the object of this hope; human fulfillment, as of now, is still a utopian abstract as experience reflects and perceives that potentialities are not only un-actualized but is practically wasted in many parts of the globe. With human fulfillment as an objective, hope then assumes a human figureone that is guarded by the PGC ensuring that, as aspirations are fulfilled, a moral milieu is created conducive to man's development; this would be a kind of ethical endorsement that would normatively respect the inherent and natural rights of man's fellow agents, in contrast to what has happened to certain totalitarian regimes which justified destruction in the name of perfection. Hope, in real terms, is not composed of empty suppositions but, rather, embodies the rationality and emotion accompanying the agent as he moves towards human fulfillment.

But how would the idea of hope, both moral and political, fit within the parameters and framework of the supreme principle? The first step to clarify these inter-relations is to establish how the moral interacts with the political as both attempt to lead the agent towards successful action. As distinctions may be arbitrary, where both moral and political affinities involve right action and policy, it can be safely asserted that the moral is directed towards a more transcendental purpose and, at the same time, has a wider conceptual arena as it has for its provenience the will of man. It is for this reason why there is a tendency to confuse ethics with religion, or deciphered negatively, violations of religious practices with immorality. The political, on the other hand, involves action which has for its purpose an efficient and effective governance of man's relation with his fellow man. Historically, there had been transcendental ends for this governance, but the modern and postmodern break of politics with religion has paved the way for more tellurian considerations. Although there have been lots of theories which have been categorized as political, ranging from the idealistic to the realist, from the elitist

\footnotetext{
${ }^{24}$ James Gardner, "Can Party Politics Be Virtuous," in Columbia Law Review, 100:3, Symposium: Law and Political Parties, (April 2000), 700.

${ }^{25}$ Shelley Burtt, "The Politics of Virtue Today: A Critique and a Proposal," in The American Political Science Review, 87:2 (June 1993), 360.
} 


\section{THE GEMRTHIAN PRINCIPLE OF GENERIC CONSISTENCY}

down to the egalitarian, and from the traditionalist to the revivalist and evolutionists, there would nonetheless be objectives to be achieved and theoretic implications for this governance to take place. ${ }^{26}$

The issues governing morality and politics center themselves upon the nature of their purposive action. While it is morality that sets the directives both for aspiration and capacity fulfillment, it is politics that grounds these directives as they clash with the complexities of a scenario where millions of agents vie for seemingly conflicting ends. Thus, the study of morality may end up being simpler, or even in the case of the PGC, ever more linear to the point that some critiques have pointed out that it is practically useless. Yet the theoretical objectives of politics remain as it is-which is to fulfill the aspirations and capacities of its citizens, to protect and establish freedom and well-being to the nation as a whole; it is only when these objectives become incoherent with both the epistemic and social forces that imposes power to attain these objectives that morality begins to dissent against political policies. The need for this power to implement these fulfillments has become the catalyst for abuse where egalitarian mandates are replaced with personalist agenda. Given this distinction, it would be innocuous to assert and describe that political hope is a longing for the fulfillment, within the ground level, of what is hoped for by morality in the theoretical scale-a kind of hope that Halpin $^{27}$ calls ultimate hope, or one that is "aimed" where identification and struggle is needed for a "here and now" particular improvement. Theorists are aware of this and it is for this struggle that certain sub-levels within political science are created; politics during times of trouble, for instance, end up with what Nelson ${ }^{28}$ calls the "political stand." Among his theses, he claims that this stand is a distinct project of political action and that theorizing is a manner by which action is fulfilled. Clearly leaning towards critical theory from the perspective of philosophy, Nelson epitomizes the form of realization which political theorists find as they struggle to bring their theories down to policies, utility to effectiveness and efficiency, and purpose down to the aspiration and capacity fulfillment of particular cases. His description of our times as "troubled transition" and that of stands as being seen in "apocalyptic terms" being the reason for its continuation, depicts both the need for change-albeit

${ }^{26}$ Smith, reacting to Terchek and Moore, argued against the idea that politics refers to the struggle by citizens to protect their conflicting interests within the framework of law and institutions; stating that Aristotle's idea is more complex than how the philosopher was understood, Smith argued that doing ethics requires the understanding of politics, and that political wisdom requires ethics. With this, the author believes that in the cognitive level, politics takes precedence because the experience of the particular is a sine qua non for the understanding of theory; and that wisdom, as a whole, must include a deductive process from the supreme moral principle. See Roland Terchek and David Moore, "Recovering the Political Aristotle: A Critical Response to Smith," in American Political Science Review, 94 (December 2000), 905-911 and Thomas Smith, "Ethics and Politics: A Response to Terchek and Moore," in The American Political Science Review, 94:4 (December 2000), 913.

${ }^{27}$ David Halpin, "The Nature of Hope and Its Significance for Education," in British Journal of Educational Studies, 49:4 (December 2001), 392.

${ }^{28}$ John Nelson, "Stands in Politics," in The Journal of Politics, 46:1 (February 1984), 106. 


\section{R. MONTAÑA}

the difficulty-and the need to establish solidly notions of purpose even though such may be eschatological. From this it is imperative that the struggles and suffering of peoples be understood by those who hold on to the reins of government because it is only through this analogical form of listening where hope finds its place into policy and realization. ${ }^{29}$ Janes $^{30}$ construes this as a challenge wherein the study of culture is conjoined with phenomenological description to pierce through the meaning of public symbols as expressions of painful feelings. The elimination of apathy for these public distress symbols is the first step to fulfill political hope.

The difficulty that theorists find in implementing the steps toward what is hoped for is founded upon the complexities inherent in contemporary life; the impact of visualization techniques, globalization of economies, nuclearization of military armaments, integration of communication lines, creation of high-velocity environments and such other progressive developments, have produced various sub-fields of ethics slowly pulling specialization away from philosophers, and at the same time placing them in the hands of professionals who mainly depend upon moral codes. Although these codes have been found to be useful in many ways, simplifying adherence and compliance to such, it still remains presumptive to unquestionably accept such even in the face of progressive transformation of issues and problems. What is needed, still, is the understanding of relational modes of moral applications, such as what Lakoff and Bruvold ${ }^{31}$ has done when they called for a thorough analysis of modern technology as the function of the primacy of politics where contingent decisions are still determinants even in the age of modern technology.

The reduction of these disconcerted moral and political elements into the supreme moral principle is tantamount to the simplification not only of moral and political analysis but also of the foundations for solutions; even though this assertion - that these problems can be basically reduced to violations of inter-related rights concerning freedom and well-being - can be charged with over-simplification of what is inherently complex, the connection between what has been dialectically implicated by man's pursuit of goods and the fundamental principles of political science can be established within the framework of the PGC without inconsistency or contradiction. ${ }^{32}$ Although

${ }^{29}$ Squatters in the Philippines, for instance, thrive in poverty within the urban setting despite the fact that the provinces are capable of providing some form of sustainability. They suffer as they squeeze in corporate jungles because of a certain hope that their lives would be better off compared to the conditions of their original abode. The government ought to listen to this clamor for personal development and not just forcibly relocate families, remaining satisfied as the minimal provisions of the law are fulfilled.

${ }^{30}$ Craig Janes, "Imagined Lives, Suffering, and the Work of Culture: The Embodied

Discourses of Conflict in Modern Tibet," in Medical Anthropology Quarterly, New Series, 13:4 (December 1999), 392.

${ }^{31}$ Sanford Lakoff and W. Erik Bruvold, "Controlling the Qualitative Arms Race: The Primacy of Politics," in Science, Technology, \& Human Values, 15:4 (1990), 382-383.

32 Contemporary world politics, for Rengger, displays a propensity to comply with international norms, regimes and regulations - a phenomenon rooted in a presumption of trust. 


\section{THE GEMRTHIAN PRINCIPLE OF GENERIC CONSISTENCY}

this paper has run through a linear, traditional and scholastic form of argumentation, with Kantian and Gewirthian elements as substances, there lies the intellectual objective of placing moral and political hope within the exemplary paradigm of the Principle of Generic Consistency.

Faculty of Arts and Letters, University of Santo Tomas, Philippines

\section{References}

Beyleveld, Deryck, The Dialectical Necessity of Morality: An Analysis and Defense of Gewirth, Alan's Argument to the Principle of Generic Consistency (Chicago: University of Chicago Press, 1991).

Burtt, Shelley, "The Politics of Virtue Today: A Critique and a Proposal," in The American Political Science Review, 87:2 (June 1993).

Gardner, James, "Can Party Politics Be Virtuous," in Columbia Law Review, 100:3, Symposium: Law and Political Parties, (April 2000).

Gewirth, Alan, "Categorical Consistency in Ethics," in The Philosophical Quarterly, 17:69 (October 1967).

Gewirth, Alan, "The Generalization Principle," in The Philosophical Review, 73:2 (April 1964).

Gewirth, Alan, Reason and Morality (Chicago: The University of Chicago Press, 1978).

Gewirth, Alan, Self-Fulfillment (USA: Princeton University Press, 1998).

Grant, Ruth and Keohane, Robert, "Accountability and Abuses of Power in World Politics," in The American Political Science Review, 99:1 (February 2005).

Halpin, David, "The Nature of Hope and Its Significance for Education," in British Journal of Educational Studies, 49:4 (December 2001).

Janes, Craig, "Imagined Lives, Suffering, and the Work of Culture: The Embodied Discourses of Conflict in Modern Tibet," in Medical Anthropology Quarterly, New Series, 13:4 (December 1999).

Lakoff, Sanford and Bruvold, Erik, "Controlling the Qualitative Arms Race: The Primacy of Politics," in Science, Technology, \& Human Values, 15:4 (1990).

Lycan, Gregory, "Hare, Singer and Gewirth on Universalizability," in The Philosophical Quarterly, 19:75 (April 1969).

Montaña, Robert, An Exploration of the Foundational Paradigms of the Gewirtbian Principle of Generic Consistency: Re-Structuring Apologies against Selected Critiques (Unpublished Doctorate Manuscript, Manila, March 2009).

Signifying further that this presumption is unstable, he offered rectifications like "shaming" to enhance this propensity. The author opines that in the ethical level, the foundations of these rectifications are found in a fundamental virtue that establishes respect for the generic features of action; in other words, adherence to the PGC as a supreme principle generates a rationalist approach to complex moral and political problems. See Nicholas Rengger, "The Ethics of Trust in World Politics," in International Affairs [Royal Institute of International Affairs 1944-], 73:3, Globalization and International Relations, (July 1997), 469). 
Nelson, John, "Stands in Politics," in The Journal of Politics, 46:1 (February 1984).

Regis Jr., Edward ed., Gewirth's Ethical Rationalism: Critical Essays with a Reply by Alan Gewirth (Chicago: The University of Chicago Press, 1984).

Regis, Jr., Edward, "Gewirth on Rights," in The Journal of Philosophy, 78:12 (December 1981).

Rengger, Nicholas, "The Ethics of Trust in World Politics," in International Affairs [Royal Institute of International Affairs 1944-7, 73:3, Globalization and International Relations, (July 1997).

Singer, Marcus, "On Gewirth's Derivation of the Principle of Generic Consistency," in Ethics, 95:2 (January 1985).

Singer, Marcus, Generalization in Ethics: An Essay in the Logic of Ethics with the Rudiments of a System of Moral Philosophy (New York: Atheneum, 1971).

Smith, Thomas, "Ethics and Politics: A Response to Terchek and Moore," in The American Political Science Review, 94:4 (December 2000).

Terchek, Roland and Moore, David, "Recovering the Political Aristotle: A Critical Response to Smith," in American Political Science Review, 94 (December 2000).

Veatch, Henry, "Paying Heed to Gewirth's Principle of Categorical Consistency," in Ethics, 86:4 (July 1976). 